\title{
Patterns of Thyroid Radioiodine Uptake: Jordanian Experience
}

\author{
Kusai M. Al-Muqbel ${ }^{1}$ and Reema M. Tashtoush ${ }^{2}$ \\ ${ }^{1}$ Department of Radiology and Nuclear Medicine, School of Medicine, Jordan University of Science and Technology, Irbid, Jordan; \\ and ${ }^{2}$ Endocrinology Clinics, King Abdullah University Hospital, Irbid, Jordan
}

\begin{abstract}
This study aimed to determine the reference range of $24-\mathrm{h}$ radioiodine uptake in euthyroid Jordanians, as well as the reference ranges for patients with diffuse and nodular hyperthyroidism. In addition, radioiodine uptake ranges were determined for those patients with Hashimoto's thyroiditis and early-phase subacute thyroiditis. Methods: The medical records of 285 Jordanian patients referred for ${ }^{131}$ I thyroid scintiscans and $24-\mathrm{h}$ radioiodine uptake tests were reviewed. The patients were referred because of a presumed-certain thyroid disorder. The patients included those who were euthyroid or who had Graves' disease, toxic nodules, Hashimoto's thyroiditis, or subacute thyroiditis. Mean radioiodine uptake and the $95 \%$ confidence interval were determined in each group. A comparison was made between groups. Results: Mean uptake ( $\pm \mathrm{SD}$ ) for the euthyroid group, toxic-nodule group, and Hashimoto's thyroiditis group was $15 \% \pm 7 \%$, $19 \% \pm 9 \%$, and $19 \% \pm 15 \%$, respectively, and these values were not significantly different from each other $(P>0.05)$. Mean uptake for the subacute thyroiditis group and Graves' disease group was $3 \% \pm 4 \%$ and $40 \% \pm 14 \%$, respectively, and both values were significantly different from other groups $(P<$ 0.05). Conclusion: The reference range of radioiodine uptake in Jordan is comparable to that reported in North America and Europe because Jordanians likely have a sufficient daily intake of stable iodine. Radioiodine uptake discriminates between euthyroid patients, subacute thyroiditis patients, and Graves' disease patients. Radioiodine uptake in toxic-nodule patients is diagnostic only if combined with image findings. Mean radioiodine uptake in Hashimoto's thyroiditis is higher than the euthyroid mean but has a wide range.
\end{abstract}

Key Words: endocrinology; radiopharmaceuticals; CNMT; radioiodine; thyroid; uptake

J Nucl Med Technol 2010; 38:32-36

DOI: $10.2967 /$ jnmt.109.069146

\section{$\mathbf{M}$} easurement of thyroid radioiodine uptake is a commonly performed test in daily nuclear medicine practice. Although the utility of thyroid scintiscans and radioiodine

Received Aug. 5, 2009; revision accepted Nov. 11, 2009.

For correspondence or reprints contact: Kusai Al-Muqbel, Department of Radiology and Nuclear Medicine, School of Medicine, Jordan University of Science and Technology, P.O. Box 3030, Irbid 22110 Jordan.

E-mail: kusai10@hotmail.com

COPYRIGHT @ 2010 by the Society of Nuclear Medicine, Inc. uptake measurement is limited for defining the cause of thyrotoxicosis in North America and Europe $(1,2)$, this test is widely used in Jordan to investigate thyroid disorders. Radioiodine uptake is influenced by stable iodine intake, which affects the body iodine pool $(3,4)$. Geographic variation in iodine intake necessitates determination of the local reference range of radioiodine uptake (5). Although every nuclear medicine laboratory is responsible for establishing its own reference radioiodine uptake range, this range was determined in North America in the 1970s (6-12) and in Europe later (13). However, there is no reported reference radioiodine uptake range in the literature in Jordan or elsewhere in the Middle East to rely on. In addition, the literature lacks any reported radioiodine uptake range in diffuse and nodular hyperthyroidism or in Hashimoto's thyroiditis in the Middle East, including Jordan. This study aimed to determine the reference range of radioiodine uptake in euthyroid Jordanians and the reference ranges for patients with diffuse and nodular hyperthyroidism, patients with Hashimoto's thyroiditis, and patients with early-phase subacute thyroiditis.

\section{MATERIALS AND METHODS}

\section{Patients}

The medical records of 285 patients referred for ${ }^{131} \mathrm{I}$ thyroid scintiscans and 24-h radioiodine uptake tests at King Abdullah University Hospital from November 7, 2004, through September 11, 2008, were reviewed. Patients were referred because of a presumed thyroid disorder. The final diagnosis of each patient was determined by the referring physician on the basis of all or part of the following: symptoms, physical examination, serial thyroid function test, ultrasonography, thyroid antibodies, and thyroid scintiscan. The patients were followed for at least 4 mo before the final diagnosis was determined, and they included those who were euthyroid or who had Graves' disease, toxic nodules, Hashimoto's thyroiditis, or subacute thyroiditis. The euthyroid group had normal thyroid function at the time of uptake measurement and one or more of the following: normal thyroid findings on scintiscans or ultrasound, a diffuse goiter, a multinodular goiter, a cold or hot nodule, and positive or negative findings for thyroid antibodies. The subacute thyroiditis group had transient thyrotoxicosis (suppressed thyroid-stimulating hormone at the time of the uptake measurement) with spontaneous recovery or development of spontaneous hypothyroidism on follow-up. All subacute thyroiditis patients underwent thyroid scintiscans and 
radioiodine uptake measurement within 1-4 wk of onset of thyrotoxic symptoms. The Hashimoto's thyroiditis group had chronic hypothyroidism (high level of thyroid-stimulating hormone at the time of uptake measurement) and high thyroid peroxidase regardless of whether the patients had a goiter. The toxic-nodule group had hyperthyroidism (suppressed thyroidstimulating hormone at the time of uptake measurement) with a multinodular goiter or a single toxic nodule. The Graves' disease group had hyperthyroidism (suppressed thyroid-stimulating hormone at the time of uptake measurement) with diffuse goiter. None of these patients had thyroid surgery or radioiodine ablation before undergoing thyroid scintiscans and radioiodine uptake measurement. The patients were asked to stop taking antithyroid medications, if any, for at least $1 \mathrm{wk}$ before undergoing the thyroid scintiscans and radioiodine uptake measurement. The patients were also asked to stop taking thyroxin (the only hormone supplement available in Jordan) 1 mo before undergoing the thyroid scintiscans and radioiodine uptake measurement.

\section{Thyroid Scintiscans}

Twenty-four hours after oral administration of a 1.85- to 3.7$\mathrm{MBq}$ (50- to $100-\mu \mathrm{Ci}){ }^{131} \mathrm{I}$ capsule, 5-min static thyroid images were obtained in anterior, right anterior oblique, and left anterior oblique views while the patient was supine with the neck extended. Images were obtained by a large-field-of-view $\gamma$-camera (E.CAM; Siemens) fitted with a pinhole collimator. Image data were recorded on a $128 \times 128$ computer matrix.

\section{Thyroid Radioiodine Uptake Measurement}

Twenty-four hours after dose administration, radioiodine uptake was measured with a thyroid probe (Atomlab 950; Biodex Medical Systems). Patients were seated facing the detector, which was positioned $25 \mathrm{~cm}$ from the anterior surface of the patient's neck at the level of the cricoid. Counts were obtained at the patient's neck for $1 \mathrm{~min}$ and at the patient's thigh for $1 \mathrm{~min}$. The administered capsule was placed $25 \mathrm{~cm}$ from the detector and counted for $1 \mathrm{~min}$ just before administration. A phantom was not used. The radioiodine uptake was calculated using the following relationship: Radioiodine uptake $=[($ neck counts $[\mathrm{cpm}]-$ thigh counts $[\mathrm{cpm}]) /($ administered counts $[\mathrm{cpm}]-$ background counts $[\mathrm{cpm}])] \times 100 \%$.

\section{RESULTS}

The characteristics of the patient groups are summarized in Table 1. Generally, thyroid disorders are more common in women than men, and most of the patients are middleaged. The mean uptake values for the euthyroid group, toxic-nodule group, and Hashimoto's thyroiditis group were $15 \% \pm 7 \%, 19 \% \pm 9 \%$, and $19 \% \pm 15 \%$, respectively. There was no significant statistical difference between mean uptake values for these 3 groups $(P>0.5)$. However, both the euthyroid and the toxic-nodule groups had a narrow 95\% confidence interval (CI), whereas the Hashimoto's thyroiditis group had a wide 95\% CI (Fig. 1). The mean uptake value for the subacute thyroiditis group was $3 \% \pm 4 \%$, with a narrow $95 \% \mathrm{CI}$, and was statistically different from all other groups $(P<0.05)$ (Fig. 1). The mean uptake value for Graves' disease was $40 \% \pm 14 \%$, with a narrow $95 \% \mathrm{CI}$, and was statistically different from all other groups $(P<0.05)$ (Fig. 1). Scatter of the actual radioiodine uptake values for all subjects is shown in Figure 2.

Four euthyroid patients had extremely low radioiodine uptake $(<5 \%)$. Two of those 4 patients ( $2 \%$ and $3 \%$ uptake) underwent contrast CT $1 \mathrm{~d}$ before uptake measurement. One also had too many cold nodules as part of a multinodular goiter. The third patient (4\% uptake) was in early recovery from recent subacute thyroiditis. Regarding the fourth patient ( $4 \%$ uptake), we failed to find a cause for his low uptake value.

\section{DISCUSSION}

Thyroid scintiscans and radioiodine uptake measurement are performed more commonly in Europe than in the United States (2). This test is used mainly to identify the cause of thyrotoxicosis (1). In Jordan, this test is widely used for assessment of thyroid disorders, including thyrotoxicosis, nodule characterization, and Hashimoto's thyroiditis. Although ${ }^{123} \mathrm{I}$ has better spatial resolution and less radioactive burden to the patient than ${ }^{131} \mathrm{I},{ }^{123} \mathrm{I}$ is not used in Jordan or, probably, in many other developing countries because as a cyclotron product its availability is limited (13). Instead, ${ }^{131}$ I is widely used in Jordan and in many other developing countries for thyroid scintiscans and radioiodine uptake measurement because its long half-life $(8.1 \mathrm{~d})$ and low price make it widely available in most nuclear medicine laboratories in this region of the world.

TABLE 1

Means and Ranges of Radioiodine Uptake in Jordanian Patients

\begin{tabular}{|c|c|c|c|c|c|c|c|c|c|}
\hline Group & Total & $\begin{array}{l}\text { Mean } \\
\text { age }(y)\end{array}$ & $\begin{array}{l}\text { Age } \\
\text { range (y) }\end{array}$ & $\mathrm{F}$ & $\mathrm{M}$ & $\begin{array}{l}\mathrm{F} / \mathrm{M} \\
\text { ratio }\end{array}$ & $\begin{array}{c}\text { Uptake } \\
\text { mean } \pm \mathrm{SD}(\%)\end{array}$ & $\begin{array}{c}\text { Uptake } \\
\text { range (\%) }\end{array}$ & $\begin{array}{c}\text { Uptake } \\
95 \% \mathrm{Cl}(\%)\end{array}$ \\
\hline Euthyroid & 102 & 42.1 & $17-72$ & 77 & 25 & 3.1 & $15 \pm 7^{\star}$ & $2-56$ & $13-16$ \\
\hline Graves' disease & 108 & 37.7 & $16-80$ & 70 & 38 & 1.8 & $40 \pm 14^{\dagger}$ & $14-90$ & $37-43$ \\
\hline Toxic-nodule & 34 & 54.8 & $28-81$ & 25 & 9 & 2.7 & $19 \pm 9^{\star}$ & 6-38 & $15-22$ \\
\hline Hashimoto's thyroiditis & 20 & 35 & $14-57$ & 17 & 3 & 5.6 & $19 \pm 15^{\star}$ & $0-64$ & $12-26$ \\
\hline Subacute thyroiditis & 21 & 38.9 & $21-69$ & 13 & 8 & 1.6 & $3 \pm 4^{\dagger}$ & $0-14$ & $0-4$ \\
\hline
\end{tabular}




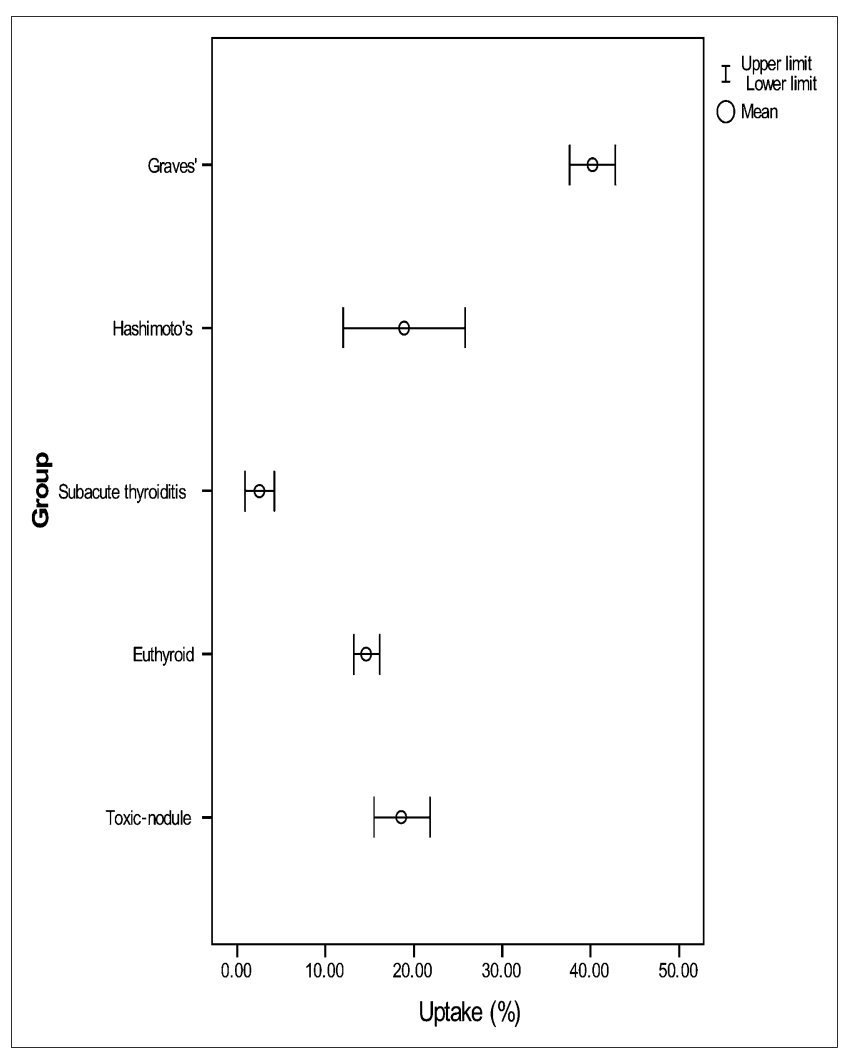

FIGURE 1. Ranges $(95 \% \mathrm{Cl})$ and mean values of radioiodine uptake in Jordanian patient groups.

Dosing for thyroid scintigraphy in our laboratory is within the range recommended by the Society of Nuclear Medicine procedure guideline (14).

Although use of a neck phantom is recommended during radioiodine uptake measurement (15), a phantom was not used in our laboratory. Chervu et al. (16) studied radioiodine uptake measurement with and without a neck phantom. They found that a neck phantom made the Compton scatter peak more prominent and closer to the total absorption peak for both ${ }^{123} \mathrm{I}$ and ${ }^{131} \mathrm{I}$. In addition, this finding was more obvious with ${ }^{123} \mathrm{I}$ than with ${ }^{131} \mathrm{I}$, because ${ }^{123} \mathrm{I}$ has lower photon energy. The use of a wide window setting, particularly with ${ }^{123} \mathrm{I}$, would result in the inclusion of a significant amount of scatter. Moreover, they reported that 8 patients underwent radioiodine uptake measurement 3 times using 3 different phantoms and the radioiodine uptake values were different in the 3 measurements. They recommended that the neck phantom should be standardized in terms of the depth of capsule housing and the resulting attenuation factor.

In Jordan, nuclear physicians frequently are asked by clinicians what the reference range of radioiodine uptake is. There is no reported reference range for radioiodine uptake in this region of the world. It is well known that there is geographic variation in stable iodine intake, which significantly affects the body iodine pool and the value of radioiodine uptake (3). Radioiodine uptake is lower in a region with an adequate amount of iodine in the food than in an iodine-deficient region (4). In fact, the geographic variation and the possibility of changing dietary iodine intake in healthy persons point to the necessity of current and local determinations of the "reference range" of the thyroidal uptake of radioiodine if the results of this thyroid function test are to be properly interpreted (5). For this purpose, we reviewed the results of thyroid scintiscans and radioiodine uptake measurement performed in northern Jordan from 2004 to 2008. The mean thyroid radioiodine uptake in euthyroid subjects in our laboratory was $15 \% \pm$ $7 \%$, with a narrow $95 \%$ CI $(13 \%-16 \%)$. Our euthyroid mean is comparable to means reported in the 1970s in North America $(6-11)$ and in later studies using ${ }^{131} \mathrm{I}$ in Europe (12). But our euthyroid mean is smaller than the mean reported in one study that used ${ }^{123} \mathrm{I}$ in the early $1990 \mathrm{~s}$ in Boston (17).

The nuclear medicine laboratory at King Abdullah University Hospital is the only nuclear medicine facility in northern Jordan at this time. Patients referred to us are coming from urban regions, rural regions, refugee camps, mountainous regions, and desert. Regardless of this variation in the geographic regions of our population within the northern Jordanian districts, we think that our population has sufficient stable iodine intake for 2 reasons: like developed countries, Jordan adds a stable iodine supplement to table salt, and Jordan and other middle east countries have a high consumption of iodine-rich food, including bread, dairy products, sea food, eggs, and vitamin supplements $(6,10,11,17)$. Our euthyroid subjects were not selected from a healthy population. They were patients referred for investigation of a potential thyroid disorder. However, we believe that this is a realistic means of estimating thyroid radioiodine uptake in euthyroid subjects in this region.

The mean thyroid radioiodine uptake in our patients with Graves' disease was $40 \% \pm 14 \%$ with a narrow $95 \%$ CI $(37 \%-43 \%)$. As noted in other series (4), there is virtually no overlap between uptake ranges in euthyroid groups and Graves' disease groups. The mean thyroid radioiodine uptake in the subacute thyroiditis group was $3 \% \pm 4 \%$, with a narrow $95 \%$ CI $(0 \%-4 \%)$. Our data showed no significant overlap between the range of radioiodine uptake in the euthyroid group and the subacute thyroiditis group in northern Jordan, as has also been noted in other series (18). It appears that radioiodine uptake testing discriminated between Graves' disease and subacute thyroiditis in our population. However, although no significant overlap exists between the uptake ranges of the Graves', subacute thyroiditis, and euthyroid groups, there is some overlap in actual measured uptake values between these groups as noted in many other nuclear medicine laboratories. In toxic nodular hyperthyroidism, however, this may not be the case because the mean thyroid radioiodine uptake was 19\% \pm $9 \%$ and the range $(95 \% \mathrm{CI}$ of $15 \%-22 \%)$ overlapped both the euthyroid group range and the Hashimoto's thyroiditis 

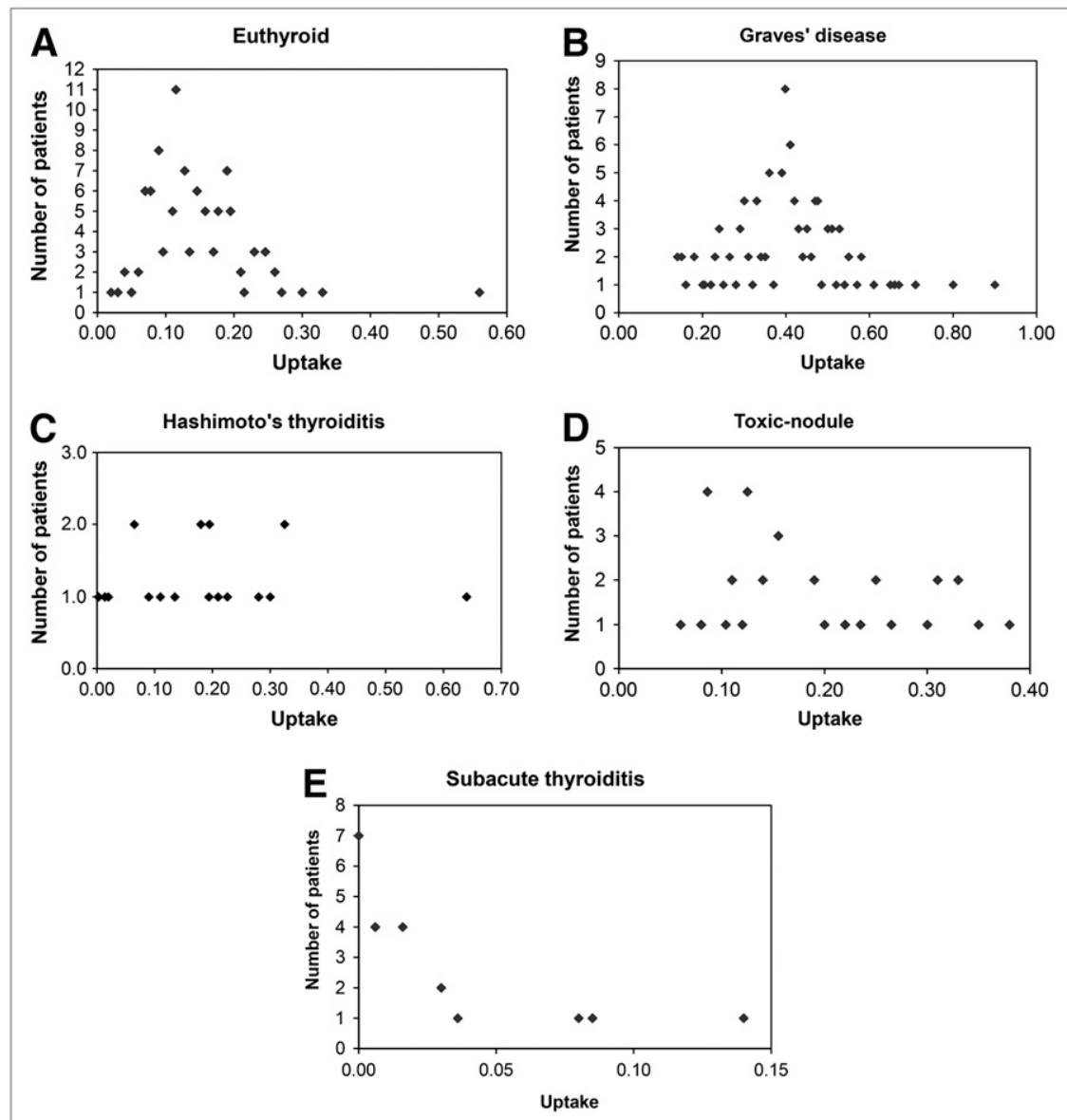

FIGURE 2. Scatter of actual radioiodine uptake values for Jordanian patient groups.

group range. But when combined with image features, the diagnosis was easily established.

The mean thyroid radioiodine uptake in the Hashimoto's thyroiditis group was $19 \% \pm 15 \%$, with a wide $95 \%$ CI $(12 \%-26 \%)$. The Hashimoto's thyroiditis group mean was slightly higher than the euthyroid mean. The Hashimoto's thyroiditis group range overlapped both the euthyroid group range and the toxic-nodule group range. It has been reported that Hashimoto's thyroiditis may cause high or low uptake $(13,19)$. One study showed that the most common finding in Hashimoto's thyroiditis is an enlarged gland with diffusely increased uptake, a pattern identical to that found in Graves' disease (20). The high avidity for radioiodine reflects chronic stimulation of a failing thyroid gland by thyroid-stimulating hormone in an attempt to produce sufficient thyroid hormone for the body's needs (20). The response of thyroid follicular cells to endogenous thyroidstimulating hormone is preserved in thyroiditis patients, and sodium iodide symporter function is suppressed by certain cytokines (13). In addition, it was found that Hashimoto's thyroiditis affects the intrathyroidal organification of iodine and is one of the most common causes of positive results on perchlorate discharge testing (13,20-22).

In this connection, we admit that several patients in our laboratory underwent ${ }^{131}$ I thyroid scintiscans and radio- iodine uptake measurement with no clear indication for these tests and that, consequently, there was no realistic justification for the subsequent high thyroid radioactive burden in those patients. The main reason for such misuse of this test in Jordan is the unawareness of referring physicians (mostly primary care physicians and general surgeons) about the updated indications for this test. From the nuclear medicine side, we could not cancel the test because cancellation likely will be misunderstood from both the patient side and the referring physician side. However, this type of practice has changed over the last few years in Jordan and referrals have become more realistic. Now we see fewer referrals for euthyroid patients and Hashimoto's thyroiditis patients unless there is a nodule.

\section{CONCLUSION}

The reference range for 24-h radioiodine uptake in Jordan is comparable to that reported in North America and Europe because Jordanians likely have a sufficient daily intake of stable iodine. According to our experience in Jordan, radioiodine uptake discriminates between euthyroid patients, subacute thyroiditis patients, and Graves' disease patients. Radioiodine uptake in toxic-nodule patients was diagnostic only if combined with image findings. Mean radioiodine uptake in Hashimoto's thyroiditis was 
higher than the euthyroid mean, but its range was wide and overlapped with the euthyroid and toxic-nodule ranges.

\section{REFERENCES}

1. Meier DA, Kaplan MM. Radioiodine uptake and thyroid scintiscanning. Endocrinol Metab Clin North Am. 2001;30:291-313.

2. Hegedüs L. Clinical practice: the thyroid nodule. N Engl J Med. 2004;351:17641771.

3. Robertson JS, Nolan NG, Wahner HW, McConahey WM. Thyroid radioiodine uptakes and scans in euthyroid patients. Mayo Clin Proc. 1975;50:79-84.

4. Milakovic M, Berg G, Eggertsen R, Nyström E. Effect of lifelong iodine supplementation on thyroid 131-I uptake: a decrease in uptake in euthyroid but not hyperthyroid individuals compared to observations 50 years ago. Eur J Clin Nutr. 2006;60:210-213.

5. Nelson JC, Renschler A, Dowswell JW. The normal thyroidal uptake of iodine. Calif Med. 1970;112:11-14.

6. Bernard JD, McDonald RA, Nesmith JA. New normal ranges for the radioiodine uptake study. J Nucl Med. 1970;11:449-451.

7. Pittman JA Jr, Dailey GE III, Beschi RJ. Changing normal values for thyroidal radioiodine uptake. $N$ Engl J Med. 1969;280:1431-1434.

8. Harvey WC, Kopp DT, Bovie WW. Further observations on the normal radioactive iodine uptake. J Nucl Med. 1972;13:548-550.

9. Wong ET, Schultz AL. Changing values for the normal thyroid radioactive iodine uptake test. JAMA. 1977;238:1741-1743.

10. Keeling DH, Williams ES. Changes in the normal range of thyroidal radioiodine uptake. J Clin Pathol. 1972;25:863-866.
11. Schober B, Hunt JA. Evaluation of the normal range of values for uptake of radioactive iodine by the thyroid gland. Can Med Assoc J. 1976;115:29-35.

12. González EP, Carmona CAR, Araya QAV, et al. Normal 131iodine uptake values at 2 and 24 hours [in Spanish]. Rev Med Chil. 2008;136:1288-1293.

13. Meller J, Becker W. The continuing importance of thyroid scintigraphy in the era of high-resolution ultrasound. Eur J Nucl Med Mol Imaging. 2002;29(suppl): S425-S438.

14. Society of Nuclear Medicine Procedure Guideline for Thyroid Scintigraphy 2.0. Available at: http://interactive.snm.org/docs/pg_ch05_0403.pdf. Accessed December $11,2009$.

15. Society of Nuclear Medicine procedure Guideline for Thyroid Uptake Measurement 3.0. Available at: http://interactive.snm.org/docs/Thyroid\%20 Uptake\%20Measure\%20v3\%200.pdf. Accessed December 11, 2009.

16. Chervu S, Chervu LR, Goodwin PN, Blaufox MD. Thyroid uptake measurements with I-123: problems and pitfalls: concise communication. J Nucl Med. 1982;23:667-670.

17. Anderson BG, Powsner RA. Stability of values for thyroid radioiodine uptake. J Nucl Med. 1996;37:805-806.

18. Brent GA. Clinical practice: Graves' disease. N Engl J Med. 2008;358:25942605.

19. Yarman S, Mudun A, Alagol F, et al. Scintigraphic varieties in Hashimoto's thyroiditis and comparison with ultrasonography. Nucl Med Commun. 1997; 18:951-956.

20. Ramtoola S, Maisey MN, Clarke SE, Fogelman I. The thyroid scan in Hashimoto's thyroiditis: the great mimic. Nucl Med Commun. 1988;9:639-645.

21. Wolff J. Perchlorate and the thyroid gland. Pharmacol Rev. 1998;50:89-105.

22. Gray HW, Greig WR, Thomson JA, McLennan I. Intravenous perchlorate test in the diagnosis of Hashimoto's disease. Lancet. 1974;1:335-337. 